\title{
ROCOV scheme for Fault Detection and Location in HVDC systems
}

\author{
J. Díaz ${ }^{1}$, O. Abarrategi ${ }^{1}$, D.M. Larruskain ${ }^{1}$, A. Perez-Basante ${ }^{2}$ and A. Rubio ${ }^{2}$ \\ ${ }^{1}$ Department of Electrical Engineering \\ University of the Basque Country UPV/EHU, Bilbao (Spain) \\ Phone/Fax number:+0034 946014970, e-mail oihane.abarrategui@ehu.eus \\ 2 Energy Unit, Tecnalia \\ Parque Tecnológico de Vizcaya, Edificio 700, 48160 Derio (Spain)
}

\begin{abstract}
A reliable DC fault protection system is essential for the development of HVDC grids. Therefore, this paper deals with the voltage derivative ROCOV scheme to locate and detect DC faults. The algorithm is able to differentiate internal and external faults considerably fast. The proposed algorithm is analyzed in a HVDC grid with different fault case scenarios. Finally, the ROCOV protection thresholds are discussed.
\end{abstract}

\section{Key words}

DC fault, Detection, HVDC Grid, Location, ROCOV.

\section{Introduction}

The effective protection of HVDC systems is essential. Nowadays, the main objective is the protection of Multi Terminal DC systems (MTDC) as they provide higher reliability through the interconnected network. Nevertheless, the protection of MTDC systems is even more complicated than point-to-point HVDC systems.

Plenty detection and location schemes for Multi Terminal HVDC systems have been proposed [1]; [2] and [3] use a current derivative based protection methodology but the DC link inductors limit the current rate. [4] presents a scheme based on voltage and presents extended simulations to classify the different thresholds. [5] presents a methodology based on voltage derivatives to locate DC faults but the methodology deteriorates if the sampling frequency decreases. Fast back-up protection based on linear discriminant analysis (LDA) is proposed in [6-8].

One of the main challenges is the identification of the line in which the fault occurs within an interval of a few milliseconds, because the target of the scheme besides the protection of the network components, is to be selective, i.e. when a fault happens only the conductor in which it occurs has to be isolated from the rest of the network.

Thus, [9] addresses the DC line protection by measuring Rate of Change of Voltage (ROCOV) and the impact of fault location on ROCOV and of current limiting reactors on the fault current are analyzed. This paper proposes a ROCOV approach in a MTDC four terminal meshed system, where different fault cases have been applied to each of the links.

\section{ROCOV}

As current rises rapidly in a highly capacitive DC network, detecting and locating the fault fast in order to know which protection to trip is very important. Because of it, it is not possible to use protection methodologies that need end-toend communication, as the propagation speeds varies depending on the transmission line parameters and it would delay the operation too much. It is important to measure the fault transient and locate the faulted line. For this purpose, overcurrent is a good indicator, so there is the possibility to use Rate of Change of Current (ROCOC). However, the ROCOC perceived by the Circuit Breaker (CB) is more or less proportional to the voltage change on the line side of the inductor, so does not give more information that the line-side voltage itself [7].

A possible solution is to use the Rate of the Change of Voltage. The variation in the ROCOV voltage change rate from an almost null steady state can be used to detect the occurrence of a fault very quickly, with only a few microseconds since the fault wave reaches the limiting inductance of the current derivative. In this way, it allows to differentiate the faults in the line that is wanted to be protected (internal faults) from other faults that are taking place in adjacent lines. This determines that the ROCOV values decrease as the fault "moves away" from the measure point.

The calculation method has been based on considering the voltage differential measured and giving the result in kilovolts per millisecond. Thus, the general expression resulting from the calculation of the ROCOV is shown in eq 1. 


$$
\frac{d V_{\text {bus }}}{d t}=\frac{V_{2}-V_{1}}{t_{2}-t_{1}}=\frac{V_{i}-V_{i-1}}{1 \cdot 10^{-8}}
$$

The value of the step time considered for the simulations $\left(\mathrm{dt}=10^{-8} \mathrm{~ms}\right)$ is included in this expression. The ROCOV will have a great application in the case of study since, if establishing a value of it as a threshold, it is possible to determine the minimum possible value measured for a fault within the primary protection zone for which the switch should turn on, and the maximum value for any fault for which the switch should not do so.

Threshold setting determines the fault detection accuracy and it is an iterative process, as it depends on the time it takes for the fault to clear. Initially, the ROCOV due to fault occurrence is determined and used to choose a series of preliminary thresholds. Then, the protection scheme can be modelled and fault clearance simulated in order to establish the maximum ROCOV value. If needed the preliminary threshold values can be modified.

\section{Simulations}

In order to test the performance of the proposed ROCOV scheme for fault location and detection, a set of simulations have been done in a four terminal meshed DC network. The Multi Terminal HVDC network incorporates two offshore wind farms and two inland converters. These are connected to the main electrical network forming a four-terminal DC meshed system. For the HVDC test system, standard parameters based on current technology [10] are used. In addition, the network includes a modular multilevel continuous converter (MMC) model in each of its terminals, as well as a cable model that depends on the frequency and that covers the different possible routes between them.

The used software is an EMT type, specifically, the PSCAD computer system. This model is a key to the study of electromagnetic flows of the DC energy system, such as those related to fault situations, protection studies or dynamic studies of networks and converters. In addition, this system guarantees a certain flexibility since it allows adapting the different components to the possible phenomena that may appear. The disposition of the study case model is shown in Figure 1. In the paper, the protection of the system is analysed, developing the basic ROCOV algorithm.

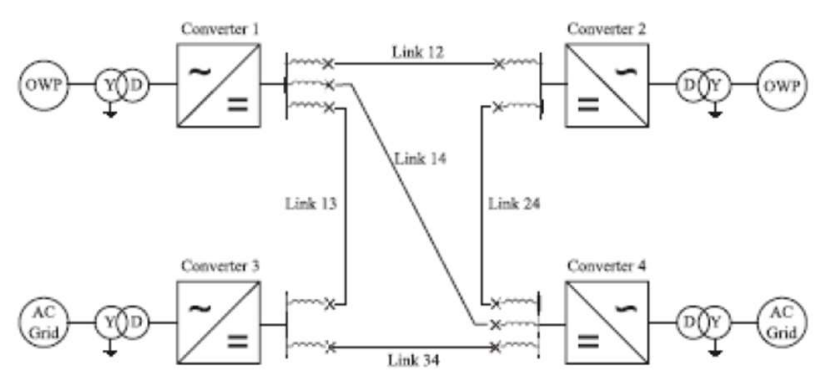

Figure 1. - Proposed HVDC network system [11]
The network consists on two links $200 \mathrm{~km}$ long (links 13 and 14), a $150 \mathrm{~km}$ link (link 24) and two $100 \mathrm{~km}$ links (links 12 and 34). Their parameters are included in Table I. A 10 $\mathrm{mH}$ filter reactance in series with the MMC converter and the DC bus is connected at cable ends. In addition, switches are included at the end of each transmission line. The series reactor for the DC switches has a value of $100 \mathrm{mH}$, similar to the case proposed in [12]. The remaining parameters relating to the AC networks and the HVDC converters are shown in Table II.

\begin{tabular}{|c|c|c|c|c|}
\hline & $\begin{array}{c}\text { EXT } \\
\text { RADIUS } \\
{[\mathrm{mm}]}\end{array}$ & $p[\Omega \cdot \mathrm{m}]$ & $\varepsilon$ rel [-] & $\mu$ rel [-] \\
\hline Core & 20 & $1,70 \mathrm{E}-08$ & - & 1 \\
\hline Insulation & 49 & - & 2,3 & 1 \\
\hline Sheath & 52 & $2,20 \mathrm{E}-07$ & - & 1 \\
\hline Insulation & 55 & - & 2,3 & 1 \\
\hline Armour & 59 & $1,8-7$ & - & 10 \\
\hline Insulation & 64 & - & 2,3 & 1 \\
\hline \multicolumn{5}{|c|}{ Table I. - Parameters of the cables }
\end{tabular}

\begin{tabular}{|c|c|c|c|}
\hline & CONV. 1,2,3 & CONV. 4 & \\
\hline Rated power & 900 & 1200 & {$[\mathrm{MVA}]$} \\
\hline AC converter voltage & 380 & 380 & {$[\mathrm{kV}]$} \\
\hline AC network voltage & 400 & 400 & {$[\mathrm{kV}]$} \\
\hline Transformer reactance & 0,2 & 0,2 & {$[\mathrm{pu}]$} \\
\hline AC network resistance & 1,77 & 1,34 & {$[\Omega]$} \\
\hline AC network reactance & 17,7 & 13,4 & {$[\Omega]$} \\
\hline Arm reactor & 84,8 & 63,6 & {$[\mathrm{mH}]$} \\
\hline Arm capacitance & 29,3 & 39 & {$[\mu \mathrm{F}]$} \\
\hline Arm resistance & 0,885 & 0,67 & {$[\Omega]$} \\
\hline Bus filter reactor & 10 & 10 & {$[\mathrm{mH}]$} \\
\hline
\end{tabular}

Table II. - Parameters of the studied network

\subsection{Base case}

In the paper a general study is performed, considering different faults at the most demanding locations, which are the beginning of each of the cables that compose the HVDC network. The fault resistance is $0.01 \Omega$, which is a minimum value that allows analyzing the worst possible fault situation in order to test the reaction of the system. This way, faults are applied at the beginning of each cable (as close as possible to the bus), since this is the point with a higher ROCOV value. Different types of faults have been simulated, nevertheless, in this paper, due to page limitation, only pole to pole faults are shown. Figure 2 and 3 show the ROCOV values $(\mathrm{kV} / \mathrm{ms})$ for an internal and external fault, respectively, since fault inception. The fault is applied at link 12 near bus 1, this way; it can be considered as an internal fault for the protections of link 12 
and as an external fault for the remaining links. The ROCOV values in link 12 are much larger than in the remaining links. Therefore, it is not possible to use just one figure for all links, as the results of the faulted link would overlap the remainder curves. In all links, various peak values can be noticed, where the highest ROCOV stands out. Anyway, the most remarkable one is the initial ROCOV peak as it will be the first value that can be detected by protections.

Pole to pole faults have been applied in all links. Table III depicts the initial and maximum ROCOV peak values in all links, when faults are located at both endings of the links. These values are measured in both endings of the links.

Table III shows that the initial peak value is approximately $64.000 \mathrm{kV} / \mathrm{ms}$ for all internal faults in the bus located beside the fault. However, this number is reduced in the bus located in the other ending of the link. Moreover, the peak ROCOV is around $93.000 \mathrm{kV} / \mathrm{ms}$ in the faulted link. These figures are maintained in all fault cases, even though the length of the links is different. The measures in the remainder links are below 500. Accordingly, there is a significant difference between the ROCOV values of faulted links and remaining links. This fact is the basis proposed for differentiating internal and external faults for protection devices. A protection system based on ROCOV algorithms can discriminate the existence of an internal fault in a link depending on the initial ROCOV peak, this value can be used as a threshold to determine a fault situation.

Besides, links that are contiguous to the faulted link show higher values than the remainder links. Thus, it is critical to analyse all cases and stablish an accurate threshold for a reliable protection system. The objective is that the CBs that are located at both endings of the faulted link trip when there is an internal fault. This way, the remaining system can continue operating safely.

The measures in both ends of the links are similar to a great extent for peak values, but they are delayed $0.66 \mathrm{~ms}$ due to the traveling waves. The initial value is detected at $0.71 \mathrm{~s}$ and the peak value at 0.7125 after fault inception.

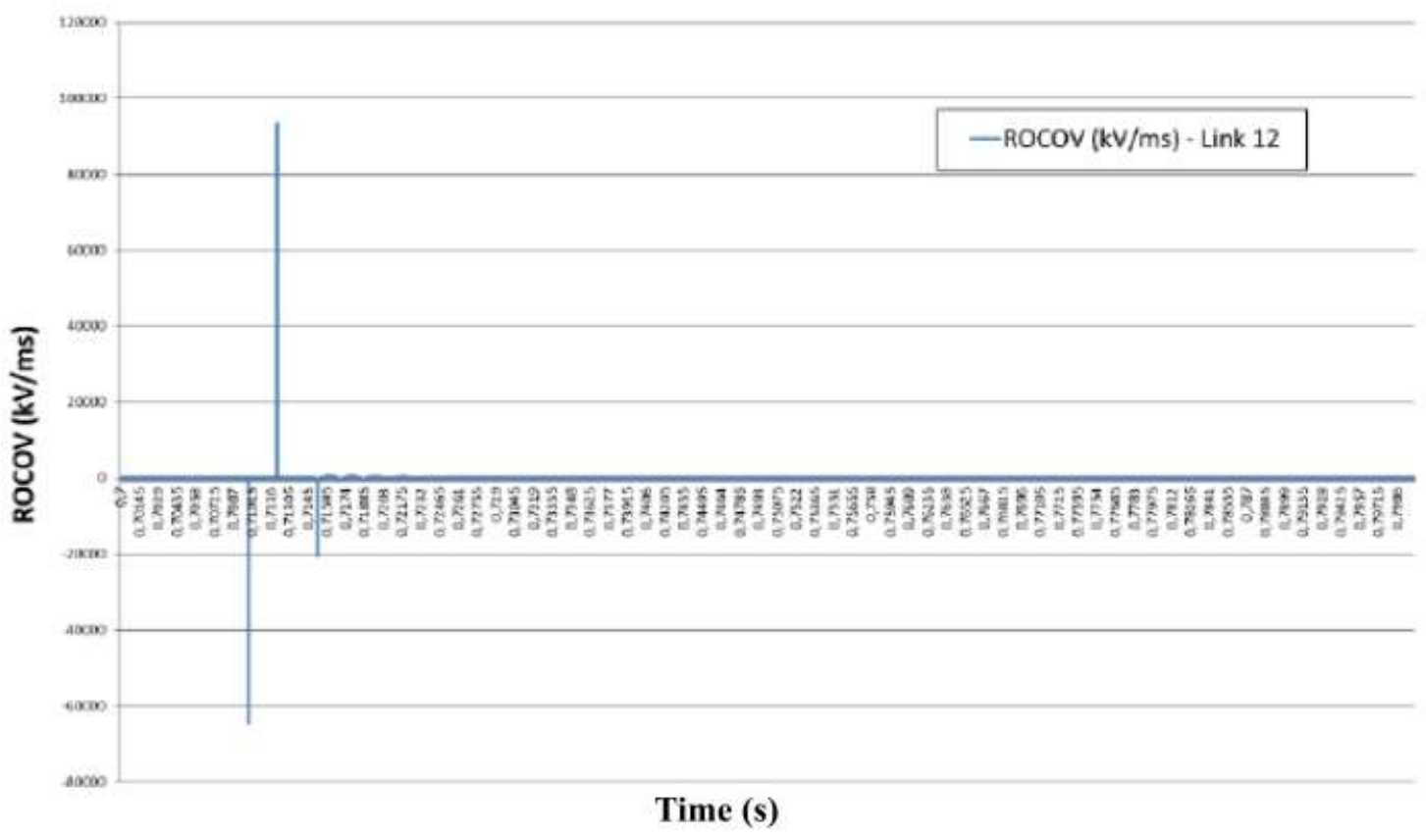

Figure 2. - ROCOV values for link 12, fault in link 12 


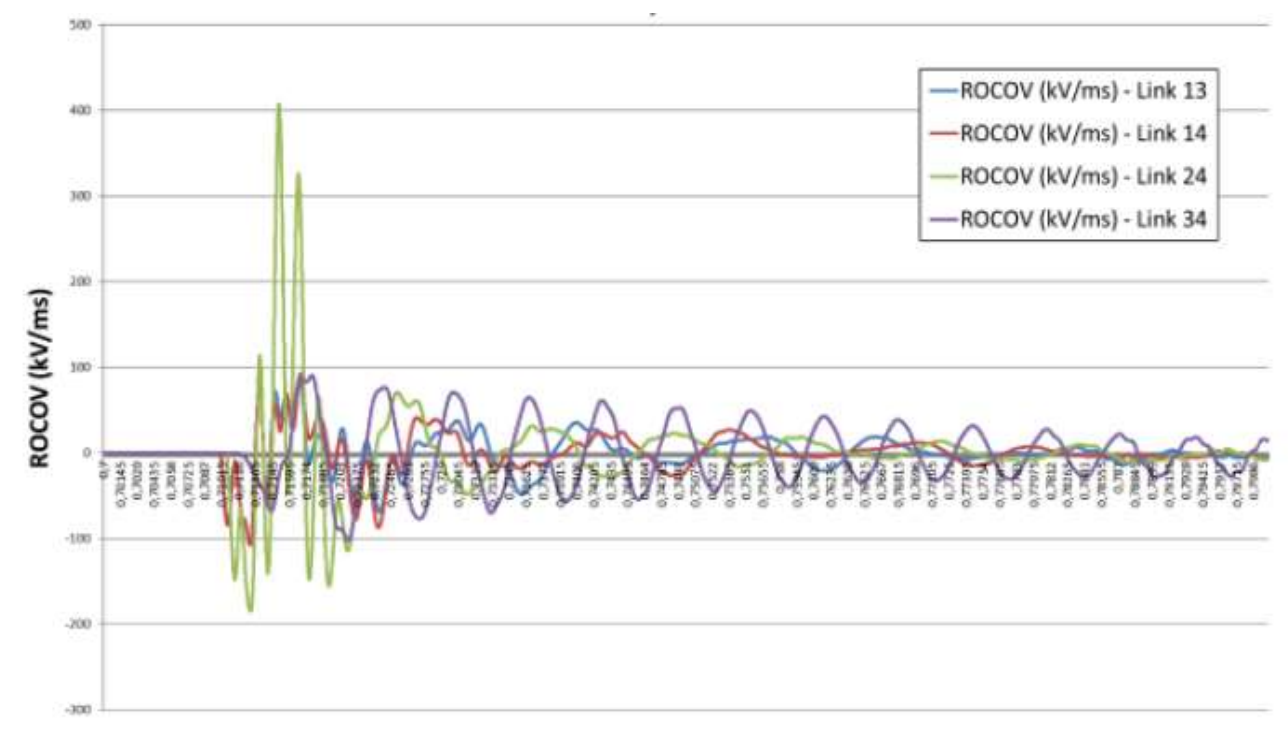

Time (s)

Figure 3. - ROCOV values for links 13, 14, 24 and 34 fault in link 12

\begin{tabular}{|c|c|c|c|c|c|c|c|c|c|}
\hline \multirow{3}{*}{$\begin{array}{c}\text { FAULT } \\
\text { LOCATION }\end{array}$} & \multirow{3}{*}{$\begin{array}{c}\text { RESPONSE } \\
\text { LINK }\end{array}$} & \multicolumn{8}{|c|}{ ROCOV $(\mathrm{kV} / \mathrm{ms})$ IN MEASURING BUS } \\
\hline & & \multicolumn{2}{|c|}{ DC BUS 1} & \multicolumn{2}{|c|}{ DC BUS 2} & \multicolumn{2}{|c|}{ DC BUS 3} & \multicolumn{2}{|c|}{ DC BUS 4} \\
\hline & & INITIAL & PEAK & INITIAL & PEAK & INITIAL & PEAK & INITIAL & PEAK \\
\hline \multirow{5}{*}{$\begin{array}{c}\text { LINK } \\
12\end{array}$} & Link 12 & $-64327,3$ & 93242,0 & $-33731,1$ & 91807,5 & - & - & - & - \\
\hline & Link 13 & $-84,6$ & 82,7 & - & - & $-99,7$ & 144,2 & - & - \\
\hline & Link 14 & $-84,5$ & 91,7 & - & - & - & - & $-99,7$ & 138,7 \\
\hline & Link 24 & $-147,8$ & 406,4 & $-146,8$ & 407,3 & - & - & $-196,2$ & 423,2 \\
\hline & Link 34 & $-67,8$ & 90,1 & - & - & $-67,6$ & 85,5 & $-60,2$ & 99,6 \\
\hline \multirow{5}{*}{$\begin{array}{c}\text { LINK } \\
13\end{array}$} & Link 12 & $-84,5$ & 275,0 & $-122,4$ & 264,9 & - & - & - & - \\
\hline & Link 13 & $-64330,4$ & 93683,8 & - & - & $-13821,9$ & 93399,6 & - & - \\
\hline & Link 14 & $-84,4$ & 154,1 & - & - & - & - & $-99,4$ & $-144,0$ \\
\hline & Link 24 & $-42,7$ & 114,9 & $-43,3$ & 114,8 & - & - & $-63,6$ & $-94,3$ \\
\hline & Link 34 & $-120,6$ & 310,5 & - & - & $-120,4$ & 313,5 & $-180,6$ & 311,5 \\
\hline \multirow{5}{*}{$\begin{array}{c}\text { LINK } \\
14\end{array}$} & Link 12 & $-84,3$ & 268,4 & $-122,2$ & 262,5 & - & - & - & - \\
\hline & Link 13 & $-84,5$ & 134,3 & - & - & $-99,7$ & $-139,6$ & - & - \\
\hline & Link 14 & $-64334,4$ & 93581,5 & - & - & - & - & $-13822,4$ & 93644,2 \\
\hline & Link 24 & $-125,2$ & 170,1 & $-125,1$ & 171,9 & - & - & $-89,8$ & $-150,6$ \\
\hline & Link 34 & $-136,8$ & 220,0 & - & - & $-136,8$ & 221,0 & $-89,4$ & 224,8 \\
\hline \multirow{5}{*}{$\begin{array}{c}\text { LINK } \\
24\end{array}$} & Link 12 & $-147,5$ & 332,2 & $-96,9$ & 337,8 & - & - & - & - \\
\hline & Link 13 & $-41,0$ & $-61,0$ & - & - & $-38,9$ & 62,9 & - & - \\
\hline & Link 14 & $-124,8$ & 146,8 & - & - & - & - & $-97,1$ & 152,6 \\
\hline & Link 24 & $-64383,1$ & 93631,5 & $-64383,1$ & 93631,5 & - & - & $-96,1$ & 238,6 \\
\hline & Link 34 & $-141,8$ & 218,4 & - & - & $-144,1$ & 218,4 & $-23073,3$ & 92920,1 \\
\hline \multirow{5}{*}{$\begin{array}{c}\text { LINK } \\
34\end{array}$} & Link 12 & $-36,9$ & $-84,6$ & $-41,9$ & $-78,4$ & - & - & - & - \\
\hline & Link 13 & $-118,8$ & 146,6 & - & - & $-101,5$ & 102,8 & - & - \\
\hline & Link 14 & $-135,3$ & 139,0 & - & - & - & - & $-110,0$ & 149,5 \\
\hline & Link 24 & $-142,2$ & 138,3 & $-143,1$ & 138,3 & - & - & $-110,0$ & 109,7 \\
\hline & Link 34 & $-63873,0$ & 93032,6 & - & - & $-63873,0$ & 93032,6 & $-33492,9$ & 92785,4 \\
\hline
\end{tabular}

Table III. - ROCOV (kV/ms) values for pole to pole faults. Base case. 


\subsection{Resistance variation}

In this section, a sensitivity analysis of the system response is shown when the resistance of the fault differs from $1 \Omega$ to $100 \Omega$. Table IV shows the initial and peak ROCOV values for pole to pole faults applied in link 12, beside bus 1 .

\begin{tabular}{|c|c|c|c|c|c|}
\hline \multirow{3}{*}{$\begin{array}{l}\text { FAULT } \\
\text { RESIST }\end{array}$} & \multirow{3}{*}{$\begin{array}{l}\text { RESP. } \\
\text { LINK }\end{array}$} & \multicolumn{4}{|c|}{ ROCOV $(\mathrm{kV} / \mathrm{ms})$} \\
\hline & & \multicolumn{2}{|c|}{ DC BUS 1} & \multicolumn{2}{|c|}{ DC BUS 2} \\
\hline & & INITIAL & PEAK & INITIAL & PEAK \\
\hline \multirow{5}{*}{$\mathrm{R}=1 \Omega$} & Link 12 & $-63404,8$ & 93222,4 & $-33249,6$ & 91803,1 \\
\hline & Link 13 & $-83,4$ & $-106,2$ & - & - \\
\hline & Link 14 & $-83,3$ & $-106,1$ & - & - \\
\hline & Link 24 & $-145,8$ & 496,1 & $-145,7$ & 406,0 \\
\hline & Link 34 & $-67,3$ & $-100,8$ & - & - \\
\hline \multirow{5}{*}{$\mathrm{R}=5 \Omega$} & Link 12 & $-59932,3$ & 93137,8 & $-31436,7$ & 91784,1 \\
\hline & Link 13 & $-79,1$ & $-91,5$ & - & - \\
\hline & Link 14 & $-79,0$ & $-91,3$ & - & - \\
\hline & Link 24 & $-138,1$ & 414,3 & $-138,1$ & 414,3 \\
\hline & Link 34 & $-63,7$ & $-92,6$ & - & - \\
\hline \multirow{5}{*}{$\mathrm{R}=10 \Omega$} & Link 12 & $-56092,3$ & 93252,5 & $-29430,8$ & 91836,3 \\
\hline & Link 13 & $-74,2$ & $-231,3$ & - & - \\
\hline & Link 14 & $-74,2$ & $-231,2$ & - & - \\
\hline & Link 24 & $-129,7$ & 433,8 & $-129,7$ & 433,8 \\
\hline & Link 34 & $-78,1$ & 115,8 & - & - \\
\hline \multirow{5}{*}{$\mathrm{R}=20 \Omega$} & Link 12 & $-49720,8$ & 93121,8 & $-26100,1$ & 92572,2 \\
\hline & Link 13 & $-66,2$ & $-233,0$ & - & - \\
\hline & Link 14 & $-65,9$ & $-232,0$ & - & - \\
\hline & Link 24 & $-115,5$ & $-126,0$ & $-115,7$ & $-126,0$ \\
\hline & Link 34 & $-53,3$ & $-91,5$ & - & - \\
\hline \multirow{5}{*}{$\mathrm{R}=30 \Omega$} & Link 12 & $-46649,0$ & $-46649,0$ & \begin{tabular}{|l|}
$-23446,8$ \\
\end{tabular} & 92362,0 \\
\hline & Link 13 & -597 & $-204,7$ & - & - \\
\hline & Link 14 & $-59,6$ & $-207,6$ & - & - \\
\hline & Link 24 & $-104,7$ & $-264,6$ & $-103,9$ & $-264,6$ \\
\hline & Link 34 & $-33,4$ & 167,7 & - & - \\
\hline \multirow{5}{*}{$\mathrm{R}=40 \Omega$} & Link 12 & $-40516,1$ & $-40511,1$ & \begin{tabular}{|c|}
- \\
2128207 \\
\end{tabular} & 92254,3 \\
\hline & Link 13 & $-54,4$ & $-177,9$ & - & - \\
\hline & Link 14 & $-54,3$ & $-184,1$ & - & - \\
\hline & Link 24 & $-94,8$ & $-221,2$ & $-94,6$ & $-217,6$ \\
\hline & Link 34 & $-29,9$ & $-115,3$ & - & - \\
\hline \multirow{5}{*}{$\mathrm{R}=50 \Omega$} & Link 12 & $-37083,4$ & $-37083,4$ & $-19484,5$ & $-19484,5$ \\
\hline & Link 13 & $-49,59$ & $-172,4$ & - & - \\
\hline & Link 14 & $-49,0$ & $-178,4$ & - & - \\
\hline & Link 24 & $-87,2$ & $-180,7$ & $-87,2$ & $-180,7$ \\
\hline & Link 34 & $-28,6$ & $-161,8$ & - & - \\
\hline \multirow{5}{*}{$\mathrm{R}=100 \Omega$} & Link 12 & $-26084,2$ & $-26084,2$ & $-13697,5$ & $-13697,5$ \\
\hline & Link 13 & $-35,3$ & $-87,7$ & - & - \\
\hline & Link 14 & $-35,2$ & $-79,4$ & - & - \\
\hline & Link 24 & $-61,8$ & $-105,8$ & $-61,6$ & $-106,4$ \\
\hline & Link 34 & $-21,6$ & $-121,0$ & - & - \\
\hline
\end{tabular}

Table IV. - ROCOV ( $\mathrm{kV} / \mathrm{ms})$ values for different fault resistances in pole to pole faults in link 12 .

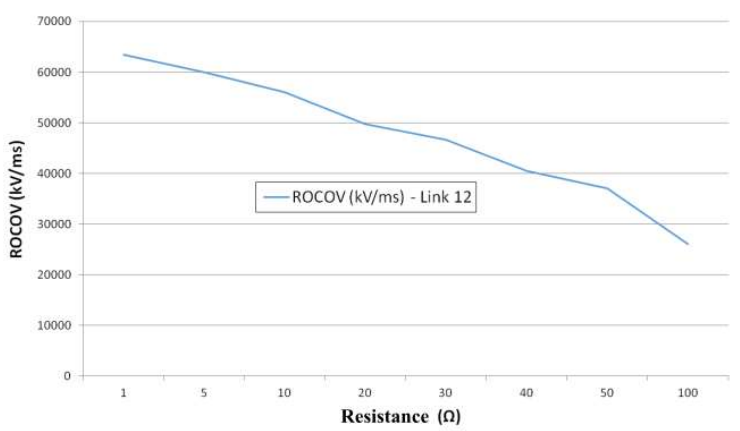

Figure 4.- ROCOV development for different fault resistances.

Finally, Fig. 4 outlines the initial ROCOV values of the pole to pole fault in link 12. All measures are taken in bus 1. The figure shows that larger fault resistances lead to lower ROCOV peak values, as expected. Therefore, high resistance faults will have low ROCOV values. In consequence, these faults can be more challenging to detect.

\section{Conclusions}

This paper proposes the use of a ROCOV algorithm to protect HVDC grids. A four-terminal MTDC has been used as a study case. An extensive analysis of fault cases show that the proposed algorithm is particularly fast discriminating internal and external faults. The paper results include the most demanding possible faults, consequently, pole to pole faults have been applied in all links. The ROCOV values for each fault case have been measured in all busses. The length of the cable is not considered a relevant factor in view of the fact that the values of ROCOV in each case have been very similar.

The value that indicates the existence of a fault is the initial peak of the voltage derivative. This value can be measured $0.71 \mathrm{~ms}$ after fault inception in all links. Therefore, the demanding protection requirements are fulfilled. As a conclusion, the ROCOV scheme can be determined to be fast enough for a reliable HVDC protection system.

Moreover, the time in which the initial value appeared and the peak value of the fault has been the same in all fault cases. This is valuable for determining the exact fault inception time. Furthermore, the maximum values of ROCOV appear on the cable where the fault occurs, as expected. This is the basis for differentiating internal and external faults. 


\section{Acknowledgement}

The authors thank the support from the Spanish Ministry of Economy, Industry and Competitiveness (project ENE2016-79145-R AEI/FEDER, UE) and GISEL research group IT1083-16), as well as from the University of the Basque Country UPV/EHU (research group funding PPG17/23).

\section{References}

[1] M.J. Pérez Molina, D.M. Larruskain, P. Eguia Lopez, O. Abarrategi, M. Santos-Mugica, "A comparison of non-unit and unit protection algorithms for HVDC grids" AEIT HVDC International Conference 2019, Florence, Italy, May 9-10, 2019.

[2] L. Tang, "Control and protection of multi-terminal dc transmission systems based on voltage-source converters,' Ph.D. dissertation, Dept. Elect.Eng., McGill Univ., Montreal, Canada, 2003

[3] J. Yang, J. Fletcher, J. O'Reilly, “'Multiterminal DC wind farm collection grid internal fault analysis and protection design', IEEE Trans. Power Del., vol. 25, no. 4, pp. 2308-2318, Oct. 2010.

[4] K. De Kerf, K. Srivastava, M. Reza, "Wavelet-based protection strategy for DC faults in multi-terminal VSC HVDC systems"' IET Generat., Transmiss. Distrib,.vol. 5, no. 4, Apr. 2011, pp. 496-503.
[5] W. Leterme, J. Beerten, and D. Van Hertem, "Nonunit protection of HVDC grids with inductive DC cable termination" IEEE Trans. Power Del., vol. 31, no. 2, pp. 820-828, Apr. 2016.

[6] W. Leterme, S. P. Azad, and D. Van Hertem, "A local backup protection algorithm for HVDC grids,'

IEEE Trans. Power Del., vol. 31, no. 4, pp. 1767-1775, Aug. 2016.

[7] M. Abedrabbo, D. Van Hertem, “A primary and backup protection algorithm based on voltage and current measurements for HVDC grids" in Proc. Int. High Voltage Direct Current Conf., Oct. 2016, pp. 854-860.

[8] S. P. Azad, W. Leterme, D. Van Hertem, "Fast breaker failure backup protection for HVDC grids' Electr. Power Systs. Res., vol. 138, pp. 99-105, Sep. 2015.

[9] J. Sneath, A. Rajapakse, "Fault detection and interruption in an earthed HVDC grid using ROCOV and hybrid DC breakers' 'IEEE Trans. Power Del., 2014, DOI: 10.1109/TPWRD.2014.2364547

[10] M. Monterrubio. "Transporte de energía eléctrica en corriente continua. Enlaces HVDC-VSC". Proyecto fin de carrera. Universidad de Valladolid. Marzo, 2013.

[11] J. Häfner, B. Jacobson, "Proactive Hybrid HVDC Breakers: A key innovation for reliable HVDC grids," in CIGRÉ Bologna Symp., Bologna, Italy, 13- 15 Sep. 2011, [12] N. Ahmed, S. Norrga, H.-P. Nee, A. Haider, D. Van Hertem, L. Zhang, L. Harnefors, "HVDC supergrids with modular multilevel converters the power transmission backbone of the future," in Proc. IEEE SSD, 20-23 Mar. 2012. 